\title{
Resilient Leadership: Theory and Innovation in Chinese Higher
}

\section{Education}

\author{
Shuya $\mathrm{Li}^{1} *$ Ogunniran Moses Oladele ${ }^{2}$ \\ 1. The Chinese University of Hong Kong, Email: serashuya@gmail.com
}

2. *Corresponding Author: Mahatma Gandhi Institute of Education and For Peace and Sustainable Development MGIEP 35 Ferozeshah. India. (UNESCO). ogunniranmoses1985@yahoo.com

\begin{abstract}
The research gaps in the connection between resilient leadership and innovation necessitate this paper, especially as the world is moving away from the global pandemic of COVID-19. This paper has successfully reviewed theory and innovation under resilient leadership in Chinese higher education. The paper explores various concepts under resilient leadership. Variables and indicators of resilient leadership were reviewed. It also focuses on related models and theories under resilient leadership. Three models of resilient leadership: the compensatory model, challenge model, and the protective factor model were examined. Constructivist self-determination theory serves as a guiding principle for this paper. This theory was derived from social learning theory, which integrates psychoanalytic theory, constructivist thinking, and cognitive development theory. The paper also delved into resilient leadership and various online educations in Chinese higher education.
\end{abstract}

Keywords: Resilient Leadership, Innovation in Online Education, Innovation in Chinese Higher Education

DOI: $10.7176 / \mathrm{JEP} / 12-10-14$

Publication date: April $30^{\text {th }} 2021$

\section{Introduction}

The year 2020 is a remarkable one in the world's history in terms of how leaders across countries respond to the COVID-19 pandemic. China, a country that has experienced the greatest economic growth globally in recent decades, with project 211 and Project 985 policies which revealed a key role in the qualitative advances of Chinese Higher Education was hit with global pandemic (Danilo de \& Qiang, 2020). There are different responses in different countries, but lockdown became the order of the day in virtually all the over two hundred affected countries. The education sector was seriously affected during this period, as all levels of schools (nursery, primary, secondary and higher education) were in total lockdown. During this period, online education became rampant with its different challenges. After some months, schools started to reopen gradually across the world. The stakeholder in the education sector came up with new policies on education (Xue, Li \& Xu, 2020).

In China, the Ministry of Education too came up with the Novel Coronavirus Epidemic Prevention and Control Group office. This office is saddled with the responsibility of implementing online education actions for the novel coronavirus pandemic control and prevention in all types of schools. As the education sector leaders are in a hurry to get out of the pandemic, they are expected to consider some vital conditions that are needed to be met before delving into online education. Essential requirements like what will make the way in which Chinese people adapt to this online education easily, known as informationization, educational infrastructure, human resources, educational resources, contents of the policy formulation and implementation of the educational informationization in China (Xue, $\mathrm{Li} \& \mathrm{Xu}, 2020$ ). It is based on the aforementioned issues that necessitate this paper to examine resilient leadership in terms of theory and innovation in Chinese higher education. This paper is divided into several parts. The first part explores the concept of resilient leadership. The second part focuses on resilient leadership models and theories. The third part concentrates on resilient leadership and online education in Chinese higher education and conclusion and recommendation round off the paper.

\section{The Concept of Resilient leadership}

Resilience has been defined as the ability to come back from frustration, adversity, and misfortune. It is an essential tool for an effective leader. Literature has demonstrated that there is a positive relationship between the leaders' stress and leaders' abilities to maintain resilience in the face of prolonged contact with adversity (Ackerman \& Maslin-Ostrowski, 2002; Greene, 2003; Heifetz \& Linsky, 2004; Ledesma, 2012). 
The concept of resilience is not only associated with recovery, survival, and thriving but also describes the stage at which leaders maybe, during or after facing adversity. Thriving on itself refers to leaders' ability to move beyond their original level of activity to a higher level and to function in that level despite repeated exposure to various stress that may occur (O'Leary, 1998). Some researchers in their various works have suggested a series of variables that exhibit the characteristic of resilience. These variables are so numerous that this paper has a sub-section for variables for resilient leadership. Some of these variables are strong coping skills, positive selfesteem, a sense of coherence, hardiness, strong social resources, self-efficacy, adaptability, optimism, determination, risk-taking, perseverance, low fear of failure and a strong tolerance of uncertainty (O'Leary, 1998; Patterson, Patterson \& Collins, 2002; Ungar, 2004; Masten, 2005).

\subsection{Origin of Resilience}

According to Greene, Conrad, Livingstone, Burton, Watkins, Blundo \& Riley (2002), resilience is originated from the Latin word "resilience," that is to the pliant or elastic quality of a substance. Resilience has been defined as a class of phenomena characterized by good outcomes despite severe threats to the adaptation of development (Masten, 2005). Another researcher who delved more on psychiatric risk refers to the term as what is used to describe the positive tone of differences among leaders to the way they respond to stress and adversity (Rutter, 1987). Resilience has been identified as the ability to bounce back from misfortune, adversity, and frustration (Janas, 2002).

Resilience has again been defined as the capacity to face people who portray stress without major negative disruption in functioning (Perry, 2002). In the literature of the developmental, resilience is typically defined as protective psychological risk factors that bring out the development of features like healthy personality and positive outcomes (Bonanno, 2004). Greene et al. (2002) use resilience synonymously with adaptation, positive coping, and persistence. In essence, researchers on resilience agree that it is concerned with personal variations in the way we respond to risk. While some people succumb to adversity and stress, others will still survive them and respond well to the difficulties associated with life's calamities (Rutter, 1987).

\subsection{Historical Perspectives of Resilient Leadership}

Several disciplines have researched hypothetical circumstances that surround resilience. For instance, in the psychology field of study, a resilient leader has been defined as a leader who can bounce back and withstand hardship by repairing himself (Higgins, 1994; Wolin \& Wolin, 1993). In the psychiatry field of study, Flach (1988) opines that resilient leadership is the biological and psychological strength of leaders in humans' use to coordinate successful change. In the developmental psychopathology field of study, resilient leadership refers to leaders' ability to withstand threats and challenges while maintaining an integrated and internal sense of self (Garmezy \& Masten, 1986). In the human development field of study, resilient leadership has been defined as leaders' ability to successfully cope with adversity (Werner \& Smith, 2001). In the change management field of study, resilient leadership has been viewed as leaders' ability to exhibit both flexibility and strength during the change process while exhibiting minimal dysfunctional behavior (Conner, 1993).

One of the fields of study that contributed to the discussion of resilient leadership is the medical field of study. Flach (1988) and O'Leary \& Ickovics (1995) defined resilient leadership as leaders' ability to acknowledge the purpose of pain, recognize it, and tolerate it for a certain period of time until normalcy begins to return. In the epidemiology field of study, resilient leadership has been defined as leaders' ability to overcome stress and rise above the challenges (Rutter, 1979). In the nursing field of study, resilient leadership has been defined as leaders' ability to revive power to respond to the external and internal environment to growth, development, and survival (Jones, 1991).

The social sciences field of study generally defined resilient leadership as leaders' ability to recover from negative incidences that are experienced and become stronger while overcoming these negative incidences (Henderson \& Milstein, 1996). The educational administration field of study contributed to the definition of resilient leadership by applying resilience theory to principals to thrive during difficult situations (Geocaris, 2004). Isaacs (2003) also used resilient leadership under resilience theory to investigate the type of relationship among the dimensions of the resilience of leadership in high-school toward strengthening the leadership abilities.

The connection between resilient leadership and their efficacy had been examined by Goldstein (2003). Nishikawa (2006) investigated the external and internal variables utilized by thriving leaders and described the 
organizational characteristics that support thriving as perceived by leaders in basic schools. Schaid (2005) again examined resilient leadership in the field of psychology and how it was applied to the impact of spiritually centered leaders in the education field. The above studies had found the relationship between resilient leadership and other variables like efficacy, spirituality, external and internal variables but none of the studies had examined the connection between resilient leadership and innovation. This creates a gap for this paper to fill. The paper, therefore, investigates resilient leadership: theory and innovation in Chinese higher education.

\section{Resilient Leadership Models and Theories}

For the purpose of this paper, three models of resilient leadership will be examined. The models are the compensatory model, challenge model, and the protective factor model (O'Leary, 1998). These models will present how leaders in china were able to overcome the challenges of Covid-19, especially in the education sector through innovation like online education.

\subsection{The Compensatory Model}

This model views resilience as a factor that will neutralize the rate at which leaders are exposed to risk. Factors that are associated with risk and compensatory contribute to the outcome of the result to expect after the crisis. Four main features are used for resilient leaders, whether young or old. The first of these features is the tendency to perceive experiences in a positive light even when they were suffering. The second of these features is an active approach toward problem-solving. The third of these features is the ability to gain other people's positive attention. While fourth and the last of these features is a strong reliance on faith to maintain an optimistic world view (Werner and Smith, 2001). Factors like optimism, intellectual competence, empathy, insight, self-esteem, mission, perseverance, and determination have been identified as compensatory factors (Ungar, 2004).

\subsection{The Challenge Model}

It proposes that a risk factor that is not too severe has the ability to develop the rate at which leaders adapt to crisis. The challenge model basically prepares the leaders with the experience to handle future challenges that may occur (O'Leary, 1998).

\subsection{Protective Factor Model}

This protective factor model focuses on the interaction that exists between protection-related factors and riskrelated factors. This interaction neutralizes the effect of risk exposure and lowers the chance of a negative outcome on the leaders (O'Leary, 1998). This protective factor model of resilient leadership is derived from systems theory and developmental literature. This indicates that the resilient leadership's protective factor model advocates healthy leadership characteristics and positive outcomes crisis (Bonanno, 2004; Ungar, 2004). The protective factor model of resilient leadership also identified emotional management that is skills related, academic and job skills, intrapersonal reflective skills, ability to restore self-esteem, life skills, planning skills, and problem-solving skills (Ungar, 2004).

\subsection{Resilient Leadership and Thriving}

A study on resilient leadership will not be completed without delving into the concept of thriving. The Leaders in china and across countries respond to the COVID-19 pandemic, especially in the education sector, with different responses. Thriving in this sector will not be achievable without resilient leaders who can overcome the threats posed by the pandemic. Scientific studies on coping paradigms and vulnerability have focused on thriving as a positive transformation that is obtained from the experience of adversity among leaders (Nishikawa, 2006).

When leaders face challenges, the literature on thriving has identified three different ways of addressing their challenges. These three different ways are to survive the incident, to recover from the incident, and lastly to thrive as a result of overcoming the misfortune (Nishikawa, 2006). Consequently, both first (to survive the incident) and second (to recover from the incident) are still functioning on the misfortunes that were experienced by the leaders, while the third (to thrive as a result of overcoming the hardship) has witnessed transformation as a result of a cognitive shift in response to misfortunes. Leaders in this third category can now have a powerful sense of belief by refocusing priorities. 
Thriving among leaders usually results from a calamity where the leaders' identity and a sense of purpose are questioned (O'Leary, 1998). After such calamity, survival, and healing in the midst of suffering will follow. Then the true transformation that includes trust, hope, connection, the renewal of faith, reconstruction of meaning, redefinition of self in relation, and sense of community will follow (Saakvitne, Tennen \& Affleck, 1998).

Thriving among resilient leaders varies according to different researchers in the field. Thriving among resilient leaders is the effective mobilization of leaders and social resources in response to calamity or threat that has happened. This eventually leads to physical outcomes, positive social outcomes, and positive mental outcomes (Ickovics and Park, 1998). Thriving among resilient leaders could be referred to as faster recovery from subsequent stressors, decreased reactivity to subsequent stressors, and a consistent degree of functioning. Thriving in resilient leaders among the psychologists may reflect gains in knowledge, confidence, skills, or a sense of security in the relationship that exists among personnel. Thriving among resilient leaders is characterized by high experience as a result of calamity; these leaders, therefore, demonstrate strengthened resilience after enduring the difficulties (Carver, 1998).

\subsection{Constructivist Self-Determination Theory (CSDT) (Saakvitne et al., 1998).}

Constructivist self-determination theory is relevant in understanding how leaders in china were able to overcome the challenges of Covid-19, especially in the education sector through innovation like online education. This theory lays more emphasis on the developmental perspective that has been used to examine the link between damage and growth after a traumatic experience like adversity or misfortune. Constructivist self-determination theory is a quadruplet marriage among social learning theory, integrates psychoanalytic theory, constructivist thinking, and cognitive development theory. This marriage among these four theories emphasizes leaders' social and cultural development (Saakvitne et al., 1998). The theory proposes the uniqueness of leaders' response to trauma is determined by the meaning that those leaders ascribed to the trauma: the leaders' self-experience, age, and developmental stage; interpersonal experiences and expectations; biological and psychological resources; leaders' cultural, social and economic background (Nishikawa, 2006). Constructivist self-determination theory identified five major areas affected by the crisis or misfortune:

- Leaders' frame of reference

- $\quad$ Leaders' self-capacities

- $\quad$ Leaders' ego resources

- $\quad$ Leaders' central psychological needs

- Their perceptual and memory system

Constructivist self-determination theory understands that the way leaders adapt to trauma is connected to leadership personality and personal history in line with the traumatic event's context (Saakvitne et al., 1998). Another importance of this theory is that constructivist self-determination theory is highly relevant in the following ways: integrating nomothetic and idiographic inquiry while focusing on process and context; moderator analysis with a description of inquiry; complex multivariate hypothesis; relevant in automatic and intentional thriving; and abrupt and gradual steps toward thriving (Saakvitne et al., 1998). 


\section{Before (Covid-19) Crisis}

\begin{tabular}{|c|c|c|c|c|}
\hline \multicolumn{3}{|c|}{ Little Or No Inmovation On Education } & \multicolumn{2}{|c|}{ Few Online Education } \\
\hline \multicolumn{5}{|c|}{ Resilient Leaders'Response During (Covid-19) Crisis } \\
\hline $\begin{array}{l}\text { Synchronous Mode } \\
\text { Of Teaching }\end{array}$ & $\begin{array}{l}\text { Asynchronous } \\
\text { Mode Of Teaching }\end{array}$ & $\begin{array}{c}\text { Online Flipped } \\
\text { Classroom Mode of } \\
\text { Teaching }\end{array}$ & $\begin{array}{l}\text { Online Tutoring- } \\
\text { based Mode of } \\
\text { Teaching }\end{array}$ & $\begin{array}{l}\text { Free Online } \\
\text { Courses }\end{array}$ \\
\hline
\end{tabular}

\section{Resilient Leaders' Response After (Covid-19) Crisis} In-depth Integration Of New Technology (AI) And Teaching

\section{Integration Of Online And Offline Teaching}

Information

Techuology Literacy

Training For

Stakeholders

\section{Infonmation-based} Education

Figure 1: Theoretical framework showing how leaders in education sector were able to overcome the challenges of Covid-19 through online education

Figure 1 above reveals the theoretical framework for this study. It focuses on understanding how leaders (stakeholders in the education sector) in China were able to overcome the challenges of Covid-19 through innovation in online education. It is cleared in the figure that there was little or no innovation in education as a result of a few online education before the (Covid-19) crisis. The education sector stakeholders were able to face the crisis with different solutions like synchronous mode of teaching, asynchronous mode of teaching, online flipped classroom model of teaching, online tutoring-based mode of teaching, and free online courses during (Covid-19) crisis. These leaders in the education sector were resilient by addressing the crisis and thrive after the (Covid-19) crisis. This is true because of their responses after (covid-19) crisis. Responses like in-depth integration of new technology (Artificial Intelligence) and teaching, integration of online and offline teaching, information technology literacy training for stakeholders, and information-based education.

China has obviously come out with a series of policy documents on educational informatization to improve leadership, organization, and the general coordination of educational informatization. The country has concentrated on supporting institutions and encourages labour division and related institutions' integration (Xue \& Li, 2020).

\section{Variables of Resilient leadership}

The kinds of literature that address the concepts of resilient leadership and thriving do so from the perspective of internal factors and external factors. These factors contribute to the ability of leaders to thrive (Carver, 1998). Both internal factors and external factors have some indicators of thriving. Some of these indicators are presented below.

\subsection{Indicators of Internal Factors}

Indicators of internal factors in resilient leadership are defined as personality factors and self-factors. These two factors seem to have an important impact on how leaders interpret and deal with their adversities at hand. As such, these factors include but are not limited to a sense of coherence, hardiness, coping ability, the use of 
personal resources, threat appraisal, cognitive resources, and self-efficacy (O'Leary, 1998). Beardslee (1989) also presents other indicators of internal factors to include temperaments like modes of thought, positive selfesteem, response, a sense of being productive, active, and being in control of someone's environment. Furthermore, Ungar (2004) added to the following variables on self-factors: insight, optimism, empathy, intellectual competence, mission, and direction, determination, and perseverance. All these variables of internal factors are characteristics that are also reported to be present in resilient leaders.

Studies like Luthar, Cicchetti, \& Becker (2000); Masten (2005); Wyman, Sandler, Wolchik, \& Nelson (2000). have discussed internal variables associated with resilient leaders, and they are thriving. These studies continue to agree with the importance of a relatively small set of global factors related to resilient leadership. For instance, the connections to competent and caring leaders in families and communities, positive views of self, cognitive and self-regulation skills, and the motivation to be effective in the environment (Bonanno, 2004). Patterson \& Kelleher (2005) also presented other indicators that include repressors of emotional dissociation, selfenhancement, positive emotion, laughter, core personal and professional values, and personal energy (like physical, emotional, mental, and spiritual energy) and personal efficacy.

Davis, Nolen-Hoeksema \& Larson (1998) submitted that leaders possessing higher levels of the personality characteristics of hope and optimism expect positive results. These leaders believe they possess the ability to achieve their goals and more likely to experience growth in response to stress.

\subsection{Indicators of External Factors}

Researchers have presented some indicators of external factors that influence leaders' ability to remain resilient during a period of adversity. The centrality of relationships has been identified as a critical indicator of external factors that is most consistent and most compelling (Masten, 2005; O'Leary, 1998), while Bonanno (2004); Nishikawa (2006) identified social support as the most consistent and most compelling.

Carver (1998) was quoted as "A person experiencing a traumatic event finds that help from others is readily available; that the significant others in his or her life can be counted on and that the result can be a positive change in the sense of the relationships involved. The person may experience a strengthening of the sense of security in those relationships . . Perhaps, then, the person who experiences ready availability during a period of adversity acquires an enhanced sense of security in relationships. In principle, this would permit the person's future exploration to operate a more secure base." (p. 252)

According to studies on indicators of external factors that influence leaders' ability to remain resilient during the period of adversity, relationships are an important factor for leaders when they are in a period of adversity. The importance of social resources cannot be ignored, whether support is coming from a relative or an outsider (O'Leary, 1998). Also, a set of global factors have been identified as indicators of external factors that empower leaders to remain resilient during a period of adversity (Masten, 2005). Availability of external support systems as indicators of external factors that influence leaders' ability to remain resilient during crises. These external support systems' availability encourage and reinforce the necessary skills for leaders to cope during adversity (Rutter, 1987).

Resilient leadership is also connected to organizational resilience. Organizations that are: just getting by their crises, just getting back to the status quo after adversity, or just getting ahead through the development and high performance can be viewed as resilient organizations (Patterson et al., 2002). Organizational resiliency can be defined as the organization's ability to create a functioning environment that will enhance resilient leaders and staff (Nishikawa, 2006). Organizations committed to building resilient leaders and staff will encourage openness in communication, staff contributions for personal growth, and risk-taking, all with the promise of staff rewards and recognition (O'Leary, 1998).

Organizations that are resilient will structure and restructure their organizations to achieve a mission, support the development of decision-making. Such organizations will set goals, provide feedback, and have intelligencedriving mechanisms (Nishikawa, 2006). Resilient organizations employ staff that responds efficiently and quickly to change and perceive experiences constructively. These organizations ensure enough external resources, develop the ability to create solutions on the spot, expand decision-making, and develop a tolerance for uncertainty (Greene et al., 2002). 
In their research work, Howard and Irving (2013) found out that the development of leaders has been gaining recognition through the active engagement of these leaders in different adversities. These researchers argued that leaders would develop competency by overcoming difficulties that will equip them to deal with adversities and bounce back from future ones successfully. These findings indicate that organizations have a priceless influence on building their resilient leaders and staff members capable of facing future challenges and achieving the mission and vision of such organizations. It is therefore important for organizations to foster resilient leaders and other members of staff.

A robust social network that supports in times of adversities is a key factor in building resilient leaders and members of staff. Leaders are expected to be able to gain access to: their trusted colleagues, transformational development, time to reflect and collaborate with professional peers and colleagues, more opportunities for partnerships, and opportunities that demand less social isolation (Nishikawa, 2006).

\subsection{Resilient leadership and innovation in Chinese higher education}

Stakeholders in the education sector in China have exhibited qualities of resilient leaders. The reason for this is because of their responses during and after (covid-19) pandemic. Some of these responses that are related to innovation, especially online education, are presented below:

Online education plays a significant role in improving teaching and learning in rural areas of China through the synchronous mode of teaching, asynchronous mode of teaching, online flipped classroom model of teaching, and online tutoring-based mode of teaching.

Online education is education on the internet. It is electronic learning or E-learning. It is supported through electronic means of teaching and learning that rely on the internet's use to interact between tutors and pupils. In this study, online education involves a synchronous mode of teaching, asynchronous mode of teaching, online flipped classroom mode of teaching, and online tutoring-based mode of teaching.

A synchronous model of teaching is a kind of teaching where teachers form virtual classrooms with real-time synchronous lectures using video live learning platforms while students participate during the unified class time in the online learning activities by listening and learning online in real-time (Xue, $\mathrm{Li} \mathrm{\&} \mathrm{Xu}, 2020$ ). The synchronous teaching mode allows teachers to directly communicate by video or voice to teach students on the internet. This type of teaching gives a strong sense of presence, synchronous time, high interactivity, flexible and novel teaching methods to teachers and students. The synchronous teaching mode includes live-streaming teaching platforms like Tencent Classroom, ZOOM, CCtalk, Rain Classroom, and ClassIn.

Wu \& Shen (2020) has the following three suggestions for an effective synchronous mode of teaching. The first is to create communication and interaction between teachers and students in a virtual learning environment that will help students express themselves and obtain feedback from teachers. This promotes students' sense of achievement and sense of community. The second is to come out with numerous forms of learning activities that will blend online and offline activities, strengthen students' social learning, give play to the leading role of teachers, encourage students to participate in online learning interaction, implement learning activities with the learning platform as the carrier and implement students' main learning status. The third is to assist students in online learning by providing them with rich learning resources. Several schools and teachers in China have made active actions to accommodate synchronous modes of teaching, but little or nothing is done in the rural area (Meng, 2020; Wang, 2020).

Asynchronous mode of teaching refers to the art of teaching and learning where tutors make a record in a video before the teaching and send the record to students online so as to organize them to study independently, through learning fora and social software. As its name implies, it is an asynchronous teaching method for teachers and learning for students whereby students can communicate with one another. It is difficult for teachers to evaluate students effectively.

It allows students to learn at their own pace. They concentrate on the importance of their learning and replay their teachers' video clips to achieve the learning objectives. However, there are some limitations in this mode of teaching: the learning interaction is delayed, the teacher find it difficult to edit since it has been recorded and sent to the students, and the students may not understand the teacher during the period of teaching (Jiao, Zhou \& Chen, 2020; Huang, Zhang \& Shen, 2020; Xie, Yi \& Huang, 2020). Several schools and teachers in China have 
made active actions to accommodate asynchronous modes of teaching, but little or nothing is done in the rural area (Wu \& Shen, 2020).

The Online flipped classroom model of teaching refers to the total online mode of teaching that transforms the offline mode of teaching to an online mode of teaching in the class after testing. This online flipped classroom model of teaching consists of three links: before class, in class, and after class. What happens before class is that teachers present micro-videos for students to watch online in order to acquire basic knowledge and implement independent learning. What happened in the in-class is that teachers solve students' problems in pre-class learning by presenting live teaching or answering questions online, or organizing students to discuss and communicate. What happens after class is that students complete their tasks or take a test, and teachers give instructions asynchronously, and this mode of teaching blends learning together (Cheng, Pi \& Hong, 2020; Huang et al., 2020; Yu, 2020).

Online tutoring-based mode of teaching refers to one-to-many or one-on-one learning tutoring that teachers implement for students through online interactive platforms. In the online tutoring-based mode of teaching, teachers make use of WeChat, Nail, and other online learning systems to execute online remote like homework tutoring and questions and answers. This mode of teaching helps different kinds of students in achieving learning acquisition. (Jiao et al., 2020; Yin, 2020).

\subsection{Resilient leadership and innovation in Chinese higher education during pandemic}

Responses of stakeholders on the education sector in China during pandemic are presented below:

In the higher education sector of China's e-learning, by May 8, 2020, one thousand four hundred and fifty-four colleges and universities across the country have embarked on online schooling, and one million and thirty thousand teachers have made one million and seventy thousand courses accessible with a sum of twelve million, two hundred and sixty thousand courses, the number of college students that participated in online schooling totaled seventeen million, seven hundred and fifty thousand or two billion, three hundred million person-times. Again, education departments, initiatives, and social organizations at all categories took part in the online schooling with an extensive collaboration bringing forth an abundance of e-learning platforms and exceptional learning materials for students all over the nation under the administration of the Ministry of Education. Furthermore, extensive creation and implementation of instructional materials. Twenty-two e-learning platforms offering twenty-four thousand online courses together with MOOCS, SPOC, and virtual simulation experiments have been initiated by the Ministry of Education. (Yin, 2020; Wang, 2020; Wu, 2020).

The execution of e-learning during the pandemic needs the help of educational materials, teacher resources, and e-learning settings, which show an intense openness. Starting from the openness of educational materials, which made e-learning easy. The Ministry of Education, throughout the time of the pandemic, made a huge number of free online courses attainable, free teaching materials and e-textbooks for teachers and learners were provided by internet education companies and a few publishing houses consecutively yielding rich and open educational materials for students. Then, openness in manpower made the teacher resources available to students freely. Students can receive tutoring helping hands and schooling support from local education departments and school teachers, in addition to online teaching services from tutors from educational establishments and social institutions (Huang et al., 2020; Cheng et al., 2020 Cheng et al., 2020).

To give an instance, in Beijing, more than fourteen thousand outstanding teachers have been assembled through the open online tutoring for middle school teachers to provide free online questions and answers services for all grades of high schools and junior three students. Lastly, the openness of the e-learning environment I a good option during the pandemic. In the course of the pandemic, teachers at all ranks and all kinds of schools set up open learning settings for learners by implementing live-streaming courses, SPOC, MOOC, and other courses. Students can choose and get involved in online schooling all alone without the supervision of teachers. The open e-learning environment can fit into students' personalized learning needs and render personalized education for students. (Yu \& Wang, 2020; Cheng et al., 2020).

Another distinguished feature of e-learning in China in the pandemic is socialization, which showed in the following angles: First, the socialized and collaborated provision of educational resources and services. Schools, teachers, educational organizations, social institutions, and other professionals are at hand through social media to implement the various open education services such as counseling, online frequently asked questions (Wang, 2020). 
Besides, it is the socialization of students in learning pursuits that enhance social participation. Social participation means that students are involved in activities that provide interaction with teachers, learning colleagues, teaching subordinates, learning specialists, and human resources in the learning affair and acquire knowledge from interactive objects to attain social pedagogy. In e-learning, teachers motivate students to engage in concurrent online interaction and non-synchronous online discussion forum communication, and motivate students to engage in learning pursuits and interactions in the form of question and answer, collective learning, collaborative learning based on projects, learning based on inquiry and several other ways of learning (Cheng et al., 2020; $\mathrm{Wu}, 2020)$

In the course of the pandemic, in e-learning, teachers use instant texting devices to keep the communication going, give social assistance in wired teaching, make complete use of open wired teaching materials, and suggest learning associate of the same mind to students to strengthen their sense of identity (Xie et al., 2020).

\subsection{Resilient leadership and innovation in Chinese higher education after pandemic}

Responses of stakeholders on the education sector in China after the pandemic are presented below:

In the rear of the pandemic, the amalgamation of modern technology and teaching have been strengthened to attain accuracy and personalized schooling. Modern technologies represented by artificial intelligence, mobile internet technology, large data and learning survey technology aid the growth of online schooling. By intensifying the amalgamation of modern technology and teaching, personalized schooling can be achieved through students' precise diagnosis. These new technologies make teaching and learning easy for both teachers and students (Xue et al., 2020).

After the pandemic, a combination of both online and offline modes of teaching and learning has been widely used. Since online education combines both traditional and online teaching methods, it gives full attention to the learners and engages them actively involved in their learning. This combination now provides teachers the opportunity to be student cantered.

The aftermath of the pandemic has made teachers and students who were not familiar with the use of technology to embark on various training that is related to information technology literacy. The attention of stakeholders in the education sector has now been directed to teaching both teachers and students on the use of networks and technology. They also learn the use of networks and technology to retrieve information and resources and carry out online collaboration and learning interaction. After the pandemic, education may become information-based as it is now built on the internet plus online information.

\section{Conclusion}

After review of various concepts under resilient leadership, variables and indicators of resilient leadership, models and theories under resilient leadership, and innovation in online educations in Chinese higher education, this paper concludes that leaders (stakeholders in the education sector) in China have overcome the challenges of Covid-19 in the education sector through innovation in online education. The education sector stakeholders face the crisis with different solutions like synchronous mode of teaching, asynchronous mode of teaching, online flipped classroom model of teaching, online tutoring-based mode of teaching, and free online courses during (Covid-19) crisis. These leaders in the education sector have not only been resilient by addressing crises but also thrive after the (Covid-19) crisis. This is true because of their responses after (covid-19) crisis. Responses like in-depth integration of new technology (Artificial Intelligence) and teaching, integration of online and offline teaching, information technology literacy training for stakeholders, and information-based education.

China has come out with a series of policy documents on educational informatization to improve online and offline teaching, leadership, organization, and the general coordination of educational informatization. The country has concentrated on supporting institutions and encourages labour division and the integration of related institutions.

\section{Recommendations}

Given the discussion on the concepts under resilient leadership, variables and indicators of resilient leadership, models and theories under resilient leadership, and innovation in online educations in Chinese higher education, 
this paper recommends that the act of resilient leadership should manifest across other sectors. This will enable other sectors, too, to be able to thrive, as the education sector.

Future education should be built on student-centered education, national education standards, resource database, and evaluation system that would be suitable for online education.

The government should make a serious effort to empower the rural and remote areas on online education by providing information infrastructure. This will give teachers and students in the rural and remote areas the opportunities that are in the cities.

The government should make a concerted effort to improve poor online education quality so as to guarantee effective learning outcomes, improve teachers' and students' ability to use information technology for effective use of online education.

\section{Suggestions for Further Studies}

There is no doubt that this study is only a minimal contribution towards a larger goal attainment of the body of knowledge. By the nature of its conclusions and recommendations, the researcher therefore strongly suggests that more studies be carried out on the manifestation of resilient leaders across other sectors aside educational sector. Also, further studies can look into the contribution of telecommunication providers during this period when education has become information-based as it is now built on the internet plus online information.

\section{References}

Ackerman, R. H., Maslin-Ostrowski, P. (2002). The wounded leader: How real leadership emerges in times of crisis. San Francisco, CA: Jossey-Bass.

Beardslee, W. R. (1989). The role of self-understanding in resilient individuals. American Journal of Orthopsychiatry, 59, 266-278

Bonanno, G. A. (2004). Loss, trauma, and human resilience. American Psychologist, 59, 20-28.

Carver, C. S. (1998). Resilience and thriving: Issues, models, and linkages. Journal of Social Issues, 54, 245-266.

Cheng, X., Pi, Z., \& Hong, J. (2020). Influence of webcast on teaching effect - a case study of "career planning course". Modern Education Technology, 30 (2), 85-90.

Cheng, X., Pi, Z., \& Hong, J. (2020). Influence of webcast on teaching effect - a case study of "career planning course". Modern Education Technology, 30 (2), 85-90

Conner, D. R. (1993). Managing at the speed of change: How resilient managers succeed and prosper where others fail. New York, NY: Villard Books.

Danilo de, C. M., \& Qiang, Z. (2020). Chinese Higher Education: The role of the economy and Projects 211/985 for system expansion. Ensaio: Avaliação e Políticas Públicas em Educação, 28(109), 885-908. Epub May 25, 2020.https://doi.org/10.1590/s0104-40362020002802657

Davis, C. G., Nolen-Hoeksema, S., \& Larson, J. (1998). Making sense of loss and growing from the experience: Two construals of meaning. Journal of Personality and Social Psychology, 75, 561-574

Flach, F. (1988). Resilience: Discovering a new strength at times of stress. New York, NY: Fawcett Columbine.

Garmezy, N., \& Masten, A. S. (1986). Stress, competence, and resilience: Common frontiers for therapist and psychopathologist. Behavior Therapy, 17, 500-521.

Geocaris, C. M. (2004). The evolving role of the principalship: Critical insights for a new paradigm (Unpublished doctoral dissertation, Northern Illinois University, DeKalb). (UMI ProQuest Digital Dissertations, AAT 3132422). Retrieved from http://proquest.umi.com/pqdweb?did=766022421\&Fmt= 7\&clientId=1898\&RQT $=309 \&$ VName $=$ PQD

Goldstein, J. C. (2003). Voices of Catholic school principals: A phenomenological study of Catholic school principals' perceptions of efficacy and resiliency. Dissertation Abstracts International, 64(3146), 09A. (UMI No. AAT3329731)

Greene, L. (2003). More and More with Less and Less. PRINCIPAL-ARLINGTON-, 83(1), 5-5.

Greene, R. R., Conrad, A. P., Livingstone, N. C., Barton, W. H., Watkins, M. L., Blundo, R., \& Riley, J. G. (2002). An integrated approach to practice, policy, and research. Washington, DC: National Association of Social Workers Press.

Heifetz, R. A., Linsky, M. (2004). When leadership spells danger. Educational Leadership, 61(7), 33-37.

Henderson, N., \& Milstein, M. M. (1996). Management of organizational behavior: Utilizing human resources (5th ed.). Thousand Oaks, CA: Corwin Press. 
Higgins, G. O. (1994). Resilient adults: Overcoming a cruel past. San Francisco, CA: Jossey-Bass.

Howard, C. S., \& Irving, J. A. (2013). The Impact of Obstacles and Developmental Experiences on Resilience in Leadership Formation. Proceedings of the American Society for Business and Behavioral Sciences, 20(1). Retrrieved from http://asbbs. org/files/ASBBS2013V1/PDF/H/Howard_Irving(679-687). pdf

Huang, R., Zhang, M., \& Shen, Y. (2020). Research on core elements of super-large-scale internet education organizations - a case study of online education effectively supporting "school suspension without school suspension". Audio-Visual Education Research, 41 (3), 10-19.

Ickovics, J. R., \& Park, C. L. (1998). Thriving: Broadening the paradigm beyond illness to health: published quarterly for The Society for the Psychological Study of Social Issues by Blackwell Publishers.

Isaacs, A. (2003). An investigation of attributes of school principals in relation to resilience and leadership practices (Unpublished doctoral dissertation). Florida State University, Tallahassee, FL. Retrieved from http://diginole.lib.fsu.edu/etd/3863/

Janas, M. (2002). Build resiliency. Intervention in School and Clinic, 38, 117-122.

Jiao, J., Zhou, X., \& Chen, Z. (2020). A case study of "School Suspension without School Suspension" online teaching in the context of epidemic prevention and control. China Audio-Visual Education, 20 (3), 106 113.

Jones, P. S. (1991). Adaptability, a personal resource for health: Scholarly inquiry for nursing practice. An International Journal, 5, 95-108.

Ledesma, J. (2012). Narratives of longevity from the perspective of Seventh-day Adventist school administrators in North America: A multiple case study. Andrews University.

Luthar, S. S., Cicchetti, D., \& Becker, B. (2000). The construct of resilience: A critical evaluation and guidelines for future work. Child Development, 71, 543-562.

Masten, A. S. (2005). Ordinary magic: Resilience processes in development. Annual Progress in Child Psychiatry and Child Development, 56, 227-238.

Meng, J. (2020). School Suspension without Suspension: Promoting online education upgrade of primary and secondary schools. Primary and Secondary School Management. 25 (3), 31-33.

Nishikawa, Y. (2006). Thriving in the face of adversity: Perceptions of elementary-school principals. La Verne, CA: University of La Verne.

O'Leary, V. E. (1998). Strength in the face of adversity: Individual and social thriving. Journal of Social Issues, $54,425-446$.

Patterson, J. L., \& Kelleher, P. (2005). Resilient school leaders: Strategies for turning adversity into achievement. Alexandria, VA: Association for Supervision and Curriculum Development.

Patterson, J. L., Patterson, J., \& Collins, L. (2002). Bouncing back: How your school can succeed in the face of adversity. Larchmont, NY: Eye on Education.

Perry, B. (2002). How children become resilient. Scholastic Parent \& Child, 10(2), 33-35. Volume 10 Issue 2 Oct 2002

Rutter, M. (1979). Protective factors in children's responses to stress and disadvantage. In M. W. Kent \& J. E. Rolf (Eds.), Primary prevention of psychopathology: Social competence in children (Vol. 3, pp. 49-74). Hanover, NH: University Press of New England

Rutter, M. (1987). Psychosocial resilience and protective mechanisms. American Journal of Orthopsychiatry, 57, 316-331.

Saakvitne, K. W., Tennen, H., \& Affleck, G. (1998). Exploring thriving in the context of clinical trauma theory: Constructivist self-development theory. Journal of Social Issues, 54, 279- 299. doi:10.1111/j.15404560.1998.tb01219.

Ungar, M. (2004). A constructionist discourse on resilience. Youth \& Society, 35, 341-365.

Wang, R. (2020). Analysis on online teaching mode of Chinese skills course during epidemic prevention and control. World Chinese Language Teaching, 34 (3), 300-310

Werner, E. E., \& Smith, R. S. (2001). Journeys from childhood to midlife: Risk resilience and recovery. New York, NY: Cornell University Press.

Wolin, S. J., \& Wolin, S. (1993). The resilient self: How survivors of troubled families rise above adversity. New York, NY: Villard Books.

Wu, D., \& Shen, Z. (2020). Rational thinking of online teaching in Chinese Universities - based on empirical investigation of 6 universities. Education Science, 36 (2), 1-8.

Wyman, P. A., Sandler, I., Wolchik, S., \& Nelson, K. C. The promotion of wellness in children and adolescents., (pp. 133-184). Washington, DC, US: Child Welfare League of America, xxvi, 515 pp. 
Xie, Y., Yi, Q., \& Huang, Y. (2020). Characteristics, problems and innovation of the online teaching method of "school suspension without school suspension" during the epidemic prevention and control. Journal of Electronic Education, 41 (3), 20-28.

Xue, E., Li, J., \& Xu, 1. (2020). Online education action for defeating COVID-19 in China: An analysis of the system, mechanism and mode, Educational Philosophy and Theory, DOI: $10.1080 / 00131857.2020 .1821188$

Xue, E. Y., \& Li, J. (2020). Construction of education System and mechanism to proactively respond to emergencies such as COVID-19. Chinese Journal of Education, 2 (3), 1-6.

Yin, J. (2020). Experience and exploration of regional integrated promotion of online teaching in primary and secondary schools. Primary and Secondary School Management, 35 (3), 19-22.

Yu, X. (2020). Coping with COVID-19 prevention and control in universities with high-quality online teaching. People's Forum, 2020 (10), 108-109. 